\title{
Migration Model of Science and Education Management in the 'Archive Philosophy' of M.K. Petrov
}

Submitted 08/01/19, 1st revision 26/01/19, 2nd rervision 18/04/19, accepted 20/05/19

$$
\text { Didyk M.A. }{ }^{1} \text {, Erygin A.N. }{ }^{2} \text {, Muradyan O.A. }{ }^{3} \text {, Homich E.V. }{ }^{4}
$$

Abstract:

Purpose: The article deals with the features of science and education in the context of the management system, presenting not a traditional management system, but the innovative idea of a migration management model.

Design/Methodology/Approach: The study is based on the archive philosophy of M.K. Petrov. Under the conditions of 'big science', its creative potential focusing on innovations in the field of practical applications and in the education system, assigns its generation feature to cybernetic management models.

Findings: Authors presents a model of education, facing the issue of management science and education in modern conditions. It analyses the concepts of the 'science of science' and 'society scientification' in the conditions of the modern 'big science'.

Practical Implications: The results gives the view on shaping the institute of science in modern times and could be used in managing science and education at all levels.

Originality/Value: The study has a unique viewpoint on the framework of science and education, addrssing the very nature of these sociocultural phenomena.

Keywords: M.K. Petrov, cybernetics, migration ability, generation and creativity, big science, management of science and education, organizational models.

JEL codes: $120, \mathrm{Z10}$.

Paper type: Research article in Special Issue dedicated to Russian Economy. Section 4: Migration.

\footnotetext{
${ }^{1}$ Associate Professor, Department of History of Russian Philosophy and Theoretical Russian Studies, Institute of Philosophy and Sociopolitics, Southern Federal University, Rostov-onDon, Russian Federation, madidyk@yandex.ru

${ }^{2}$ Professor, Department of History of Russian Philosophy and Theoretical Russian Studies, Institute of Philosophy and Sociopolitics, Southern Federal University, Rostov-on-Don, Russian Federation,,qwe1947@yandex.ru

${ }^{3}$ Senior Lecturer, Department of Theory of Culture, Ethics and Aesthetics, Institute of Philosophy and Sociopolitics, Southern Federal University, Rostov-on-Don, Russian Federation, olesya_expert@mail.ru

${ }^{4}$ Associate Professor, Department of Philosophy and Science Methodology, Faculty of Philosophy and Social Studies, Belorussian State University, Minsk, Belarus, khomichel@yandex.by
} 


\section{Introduction}

We start our study with the words of N.V. Motroshilova being the best expert on the scientific ideas of M.K. Petrov: We lived to see the time when his key works are in hands of readers. Moreover, it is important that when even the general concepts of the science of science itself, the sociology of science started the impact into the Russian philosophical culture, M.K. Petrov quickly became one of the few Russian professionals in these areas. Except for this damned isolationism, he, without a doubt, could receive wide international recognition (Motroshilova, 2012).

Indeed, in the current global situation, science and education became an ineradicable element of existence and development. The need for integrated planning and forecasting of the future can only be based on science. Education, in turn, turns out to be both a conductor of science into culture (the so-called scientification of society), and a condition ensuring progress in science itself (thesaurus dynamics of the academic process). But how is management in science and education carried out in modern societies? Since the emergence of 'big science' (Price, 1963) before World War II, the traditional framework of its organization was established: almost all nation states created research institutes, research centers, information services, coordination councils, expert groups, ministries of science etc. But from the point of view of economic efficiency, we have a strange result: the cost of expenses per unit of scientific production increases, and the productivity of scientific labor decreases by 2 times every 10-15 years" (Petrov, 1968). Even in 1966-1968, M.K. Petrov proposed to abandon the purely bureaucratic ('cybernetic') form of organization and management in the field of science and switch to the path of 'self-organization' (migration model), with increasing its autonomy from government.

Today, the presented situation, in our opinion, has not changed fundamentally. This makes the appeal to the heritage of M.K. Petrov, reclaimed from the 'archive' by numerous publications in 1991-2017, regarding the question of the formation and functioning of a person as a creative and free personality in the current crisis conditions of the existence of science and education in the European cultural tradition, as well as the insufficiently effective way to manage them.

Thus, in the proposed article, the problem of increasing efficiency in the system of managing science and education is considered in the context of theoreticalmethodological and practical-applied ideas of M.K. Petrov.

\section{Materials and Methods}

The management of science is significant both in relation to its organization and improving the quality and effectiveness of scientific activity. The quality of scientific performance is directly related to education. A scientist plays a key role in science. But where does it come from? After all, before being in a particular 
terminal of science, and even bearing a scientist status, one must receive the appropriate special education.

At the same time, the modern philosophy of science notes that despite the existence of separate disciplines, such as, for example, philosophy of Biological sciences, the philosophy of the Natural Sciences and the philosophy of the social sciences, there is one fundamental science that is missing? Why has there been no philosophy of management sciences? According to the author, management comprises planning, organizing, staffing, leading, or directing and controlling an organization (a group of one or more people or entities) or effort for purposes of accomplishing a goal. Effective planning programme involves human resources planning desiring qualifications for positions identifying carrier paths and developing replacement charts (Nwanegbo-Ben, 2015). In fact, the theoretical perception of the importance of science has worked the way from the philosophy of science to the science studies (the science of science). In Russia, M.K. Petrov is a philosopher, methodologist, historian of philosophy and science, linguistic-cultural studies, sociologist, science expert, regional expert, major researcher and theorist in the field of sociology of knowledge and educational philosophy, writer and translator. He created a synthetic theory of 'scientification' of society.

Based on the 'philosophical science of science' approach created in 1966-68, his works provide the archive form of the author's understanding of the global problem situation in the system of management of science and education in the modern world. In the autumn of 1970, the North Caucasus Scientific Center of Higher Education as well as the methodology of systems research in the 'science of science' and its applied, educational and regional aspects fell into the spotlight of Petrov (2003; 2005; 2009). In 1974 he created a semiotic-culturological version of philosophical science of science, in 1982-1983 he developed the thesaurus dynamics as the basis of the sociology of science and education. In 1985, for the first time, the system and 'migration' methodology was presented in the "Problems of Scientification of Society" (2013). In theoretical and methodological terms, M.K. Petrov solves this problem through critical rethinking of the theory of systems. The practical task of management in this case becomes conscious and receives important incentives for the development in scientific terms, thanks to the thesaurus model of public education. Finally, proceeding to the lowest limit of the theoretical and practical attention of management theorists (enterprise, scientific structure, academic institution) is provided by M.K. Petrov in his migration model allowing the basic analogy of the 'ship-enterprise'.

The migration model of science management was basically developed by M.K. Petrov in the mid-60s. in the scientific dissertation "The Philosophical Problems of the Science of Science" and in the monograph later published under the title SelfConsciousness and Scientific Creativity (1992). The scientist designated this new model by the term 'polygenesis', but clearly showed its meaning as a paradoxical 
seizure by the cognizing subject of a unique migration characteristic of the whole existing.

In fact, the very discovery of the migration capacity of being and cognition (knowledge) is a recent event. M.K. Petrov dates him as a time of radical transformations and the emergence of completely unusual, unconventional problems in the science of the second half of the twentieth century. These problems occasionally come to philosophy from various areas of scientific research, and especially often from new areas: 'desperate cybernetics', machine translation, structural semiotics, documentaries, theories of communication, science of science, etc., and the essence of the matter is as follows: we begin to understand that, apart from the systemic values that are customary for us, which are realized in conjunction, semiotic objects also have migratory values (or ranks), which reflect not the meaning in connections, but the ability to enter into new connections to create a new meaning, the distribution of this ability all over the array of semiotic objects (Petrov, 2015).

However, this is only the tip of the iceberg. The underwater part of it is traced by M.K. Petrov at all the key stages of the development of the European cultural tradition (Petrov, 2004). In this very long history, there is a special place of 'split' cybernetically organized and carried out actions in the life of society with its landmark (cultural) superstructure and migration tendencies. The classic representative of this duality in the management of life processes is the sea ship. In the context of the specific marine existence conditions of one of the traditional civilizations (the Crete-Mycenaean one, which according to Petrov, is the direct opposite of the purely cybernetic-managerial civilization of China), the invention and widespread of Penteconter (fifty-oar-ship) created a catastrophic situation in the Aegean Sea: the fragmentation of statehood, the emergence of 'dwarf' social formations on the coasts, managed by the heroes-leaders of the pirate squads. The very deck of this large ship, in these special Aegean conditions dated from Minos to Odyssey (Petrov, 1997), clearly reveals and maximally works out two control models (of both ship and tiny social structures in general): cybernetic with negative feedback, and creative with positive feedback.

Universities played a key role in shaping the image of modern European science and Europe itself. Their current status designed to give the proper 'establishment' to any city (village) that promotes itself as a 'center', is to a large extent determined by the legendary 'university idea' associated with the symbolism of knowledge, education and prestige. The emergence of them was the first reaction to the revival of the need for secular knowledge, the first sign of the Renaissance and subsequent projects of the 'Republic of Scientists', designed to explain and change this world for the better.

The medieval university scholasticism forms the ideas about the unity and privilege of the language of scholars (classical Latin), about the universality of educational 
truths (the very idea of the university was largely connected with the need to preserve and reproduce the ancient heritage, where the 'preparatory' trivium and quadrium reproduce in their own way the Greek paideia), on provability and instrumentality of knowledge. Defining the vectors of intellectual development of Europe, universities at the same time became examples of new institutional formations based on voluntary collegiate association endowed with the right of autonomy in relation to secular and spiritual authorities. In this regard, medieval universities living by their statutes and rules as an independent 'city in the city' were one of the first analogues of the subsequent liberal corporativity (the term 'corporation' came into use due to its application for self-designation by student unions) and sovereignty.

M.K. Petrov, who carried out a magnificent reconstruction of the history of the university in the context of the dynamics of European culture, notes that so-called 'superfluous people' have become its original social basis. In the Middle Ages, they could be attributed to all those who did not fit into the rank matrix of class inheritance rules and hierarchies (younger sons, illegitimate, people of common origin who were unlucky with physical strength or skills in the inherited profession). Today they could be labeled as 'marginals', but at that time the university became a possible point of attraction for 'extra people' who found new forms of community and self-affirmation. The social status of 'scholastic', 'colleger' (college member), despite a number of restrictions related to his profession, was perceived by his contemporaries as the highest possible status for 'supersluous people' of Europe (Petrov, 2004). In historical time, the younger (landless) brothers defeated the older heirs of the aristocracy, and the 'superfluous' people became fashion trendsetters on the European Olympus.

Industrial society and capitalism, with visible opposition to university scholasticism and education, outgrew of its traditional values of a single truth and corporate democracy. In turn, capitalism transformed the image of the university professor, giving it the status of a researcher and bringing it closer to the engineering practice of using knowledge for the sake of maximum production efficiency. The reformers here were German colleges, who abandoned the traditional tutoring, transfering personal responsibility for the student to the dean's office and departments. At the same time, professors were legitimized by a certain degree of 'academic freedom' designed to develop their research potential (Petrov, 2004). Professorial reform gradually entailed a change in the entire education model, in the framework of which the general secondary education system and differentiation and specialization of the teaching staff focused on the development and expansion of knowledge in their field are formed. The school here provides pre-university training (classic paideia is replaced by a set of popular disciplines), the university provides the appropriate professional specialization. 
After three millennia of historical migration, the 'Aegean fairway' of the movement of the European cultural tradition gives almost simultaneously both the management bureaucracy and science as a social institution of renewal and creativity. The bureaucracy regulates sociality primarily within the framework of reproduction, science does not just saturate production, social and cultural spheres with new knowledge and its applications, carrying out the so-called 'learning society', but also predominantly renews, modifies, replaces old production, social, and cultural units of functioning. In other words, science originally introduces the migratory aspect of existence and knowledge into the life of society, turning it into an autonomous factor (institution) that conflicts with bureaucratic-reproductive means of existence. In his thesis "The philosophical problems of the science of science" M.K. Petrov (2006) examines in detail this phenomenon and this antagonism in relation to the systems of material production, highlighting the 'gender-free' and 'gendered' ways of its existence and development. This approach gives a look at the movement and the specifics of the development of scientific knowledge, and on the other hand, a clear relationship between science and production, the integration of science and industry, which is one of the aspects of the perception of science management in general.

The relationship between science and production, according to the 'gendered' type of development, as well as the perception of science as a direct productive force, demonstrates an active-creative view of them, against the background of the traditional 'gender-free', purely adaptive reproduction. The scientific and technological revolution is developing like a 'gendered' technological production, where production and science appear as 'female' and 'male' 'single technical populations'. It is important here that the development of the production matrix conforms to two technological processes: phylogenesis (replacement of technologies) and ontogenesis (improvement of existing technologies). According to M.K. Petrov, these processes are antagonistic, since they represent mutually exclusive forms of the hereditary mutation mechanism.

In terms of science, ontogenesis seems to be more favorable, which is designed to optimize solutions. Consequently, production and technological freedom by means of advanced technologies is necessary. These technologies are valued since they indicate the vector of movement to the ideal. In modern production, to create new technologies by means of science, the main role is played by phylogenesis. The study is not limited to existing practices and is trying to create the best technology option. Ontogenesis here appears only as a component of the overall process in improving the created technologies to a certain optimum (the limit of the economic benefits of ontogenesis), which, however, is so inconstant that it changes with each movement of the production matrix. In this vein, M.K. Petrov offers notable viewpoint: for the production, it is important to continuously quantitatively multiply homogeneous products, highlighting the repetition feature. For science, this one is also needed, but the possibility of decoding and transformation is more important, hence the process of bisociation as creating a new from scrapping and transforming 
the old becomes especially significant. In the world of discovery, science sees only laws, and this tends to develop the impersonality of creativity. Thus, in the words of M.K. Petrov, for production, the apparent world is a space mosaic and a matrix of a finite number of T-P structures, and for science, it is a work in progress or a copy of the world of discoveries. Acting as the supreme entity in technology, the T-P structure is at the heart of science, production, and the world of discovery. However, its location there is different. Acting as a universal connection of the unknown, science and production, the T-P structure forms a kind of substrate-territory, on which autonomous areas of quantitative multiplication (production), qualitative multiplication (science), a non-dissecting source of new (world of discoveries) are localized (Petrov, 2006).

Technologically, science and production are so merged in their interaction that they lose their distinctiveness. Everything changes in the economic stratum. The science here is perceived as an integral single phenomenon, along with the production. This moment allows us considering science as an anomaly in the economy, which constantly receives new benchmarks of values. Science here does not merge with production, there is a shift in patterns on their border - the incompatibility of ontoand phylogenesis, which allows excluding this merging, which reveals the autonomy of science. As a result, the relationship between production and science from the managerial side is the inevitable coordination of cybernetic and creative-migration approaches. The whole difficulty and urgency of the situation, however, lies in setting priorities. In the system of market society, this problem is solved automatically, although not always without certain losses, conflicts and paradoxes. M.K. Petrov notes that modern science demonstrates obvious problems and diseases in its 'kingdom'. There is an unstable state of science. To solve its problems, it is necessary to crystallize it in its pure form, free from these 'diseases'. It is important to note that during the life of a scientist, this problem was posed in a published article (Petrov, 1968). Even earlier the very theme of the organization and management of science was stated (Petrov, 1992; 2006).

Half a century ago, the theoretical aspect of this problem lay in the following: according to the calculations of scientists, at current growth rates of the main indicators, just by the 20-30s the experienced science would require participation in the scientific work of the entire working population and the allocation of the entire budget for science. Of course, it is an absurd: sooner or later, science will be 'saturated'. In times of M.K. Petrov, there was no clarity on how such saturation would be achieved under the conditions of intense competition between the two systems (Petrov, 1968). Today we know that the competition (at least in relation to the USSR) was completely lost by the system of socialism, which led to the collapse of the Soviet Union. But China remained and the issue of its rivalry with the USA is still open. The main thing is that science (in all developed societies-states) has stabilized, and this fact has further aggravated the competition. Now, it is not theoretically, but practically important, whether a new quality of science is ensured 
by its system of organizations, whether it offers the prospect of increasing the efficiency of scientific activity?

M.K. Petrov (1968) concluded: the very idea of organization as an activity aimed at improving the characteristics of the object being organized, i.e. of science, comes to a clear contradiction with the results. But is it possible to resolve this contradiction generally? Maintaining the accepted form of organization of science and its management is costly. But refusing organization seems impossible in principle.

The main idea of M.K. Petrov is that the rejection of the traditional (bureaucraticmanagerial) form of organization does not mean a focus on the advent of anarchy, free run, lack of control. Instead, the path of 'self-organization of science' is proposed, of course, with a sharp increase in its autonomy from government. Moreover, even within the science itself, priority is given to the 'natural laws' of its existence, adopted by the creative research groups, which, in turn, requires some internal restructuring of the science itself. Generally speaking, we need a transition from the cybernetic to the migration method of providing leadership and management of science. As a result, the decisive importance not only of the creative subject as the key figure in science, but also of the 'invisible college' i.e. the basic scientific enterprise (natural group).

\section{Results}

The future of science is a difficult, but interesting and useful task. Only having a clear future perspective, we could correctly manage our work in the present (Kapitsa, 1966). The formation of such a traditional educational strategy ('extensive') was both a prerequisite and a consequence of the development of an industrial civilization, equally in need for disciplined and literate workers for factories, provided by the school, and in need for the technocratic elite produced by universities. The university thus served as a selection and training entity.

The weak spot of any extensive model is the 'crisis of overproduction', when the quantity of goods and services produced exceeds the needs of them. The commercialization of education made it accessible to one and all. Compulsory school education, as practice has shown, does not guarantee the total literacy of the population, but only obliges teachers to issue a certificate or statement of graduation to a student by any means. A similar situation starts arising in the universities, which according to Baudrillard (2013), could be described as the last tango of value. University values (diplomas, etc.) will spread rapidly and continue circulating, almost like floating capital or eurodollars, they will spin without a reference criterion, or at least completely depreciated, but this is not important: only their circulation is sufficient, in order to create a social horizon of value. The extensive type of development condemns it to the impersonality of knowledge. The more they are specialized, the further they become detached from reality, becoming redundant 
to it. This will inevitably impact on the financing of scientific and educational projects. However, there is a chance to suspend the extensively quantitative approach to education, which is the first step to a possible image of the next transformation of European and global social reality.

In contrast to the extensive model of education, M.K. Petrov offers an intensive model. In his study "The Problems of Scientification of Society" (2013), he focuses on the basic stratum of international rhetoric in the general postulate and conceptual apparatus of science. He also critically uses the theory of system analysis to create a single tutorial-terminal of science. Here a project for reforming the education system by introducing an intensive model of 'scientification' of developed societies is proposed. More broadly, it involves solving the issue of managing science and education in modern conditions. Actually, M.K. Petrov proposed a transition to a new model of 'scientification', as the main condition for the very survival of humanity as integrity on the mental, above all, but also social and even in the long term, at the genetic level. The whole study literally breathes with today, both as a warning and as a hope.

\section{Conclusion}

Let us summarize our analysis and characterization of the presented migration model of the management of science and education in the concepts of the 'science of science' and 'society scientification' by M.K. Petrov.

1. We consider expedient the idea of M.K. Petrov on the fundamental specifics of management in the system of science and education, especially in the conditions of the modern 'big science' and the crisis of the classical European educational and cultural tradition. This is expressed in the scientist's 'step-by-step' creative trajectory: philosophy - philosophy of science - science of science - science of sciences - science of education - science of managing science and education scientific recommendations for reforming the European educational tradition.

2. Migration model expressing the new specifics of management in the system of science and education, proposed in the works of M.K. Petrova, was found in the 'natural' laws of the development of fundamental scientific knowledge: a) exponential growth: the growth of science in the rate of 'doubling' of its basic quantitative parameters in 10-15 years; b) crystallization: the existence of science in the hierarchy of frequency and ranking distribution; c) cumulation - sustainable citation network in scientific publications.

3. Practical expression of instability and the migratory mode of existence of science, significant for understanding and mastering the management of science, practical applications and education, came out most clearly as a contradiction of reproduction and creativity, reproduction and freedom. The problem of the conflict between the 
bureaucratic, 'cybernetic' (on behalf of the state) and the scientific ('migratory', consciously creative and free), allowed M.K. Petrov introducing the concept of 'scientific and technical counter-revolution'.

4. The practical task of managing science and education, which needs to be shifted to an appropriate scientific level, cannot be seriously approached with the measures of neither scientific generality nor partial scientificness of the multitude of interacting sciences. It is impossible to leave behind the transformation of the 'penteconter of the Cretan-Mycenaean and Homeric eras, the "nomothetics of the classical Hellenic polis, the 'medieval cities' and the 'universities' of the Middle Ages, shaping the institute of science in modern times and and, finally, its transition from the 'small' to the 'big science'.

\section{References:}

Baudrillard, J. 2013. Simulacra and Simulation. Tula, Publishing house Tula polygraphist, $204 \mathrm{p}$.

Kapitsa, P.L. 1966. The Future of Science. Science of Science, Moscow.

Motroshilova, N.V. 2012. Domestic philosophy of the 50-80s of the XX century and Western thought. Moscow, Academic Project, 376 p.

Nwanegbo-Ben, J. 2015. The Philosophy of Management Science: The Case of a Neglected Special Science. Journal of Philosophy, Culture and Religion, Vol. 3.

Petrov, M.K. 1968. Some problems of the organization of science in the era of scientific and technological revolution. Issues of Philosophy, No. 10.

Petrov, M.K. 1992. Self-Consciousness and Scientific Creativity. Rostov State University publ., Rostov-on-Don.

Petrov, M.K. 1997. Antique culture. Moscow, Russian Political Encyclopedia (ROSSPEN), $352 \mathrm{p}$.

Petrov, M.K. 2003. Selected Works on Theoretical and Applied Regional Studies. Rostovon-Don.

Petrov, M.K. 2004. The history of the European cultural tradition and its problems. Moscow, Russian Political Encyclopedia (ROSSPEN), 776 p.

Petrov, M.K. 2005. Region as an object of system research. Rostov-on-Don.

Petrov, M.K. 2006. Philosophical problems of the 'science of science'. The subject of sociology of science. Moscow: Russian Political Encyclopedia (ROSSPEN).

Petrov, M.K. 2009. A systematic approach to the organization of a regional research center. Rostov-on-Don.

Petrov, M.K. 2013. The problems of learning society. Proceedings of XXVI Peter's readings, Vol.1, Rostov-on-Don, Publishing House of the Southern Federal University.

Petrov, M.K. 2015. Migration capacity and scientific publication. Sociology of science and technology, Volume 6, No. 2.

Price, Derek De Solla. 1963. Little Science, Big Science. New York, Columbia University Press. 